\title{
Impact of Nurse Shortage on Patient Care
}

\author{
Yasmeen Ghafoor $^{1 *}$, Mr. Adnan Yaqoob ${ }^{2}$, Mr. Awais Bilal ${ }^{3}$, Ms. Samreena Ghafoor ${ }^{4}$ \\ ${ }^{1} \mathrm{RN}, \mathrm{MPH}, \mathrm{MSN}$, Nursing Education Department, ${ }^{2} \mathrm{BSN}, \mathrm{MSN},{ }^{3} \mathrm{HR}$ Professional \\ ${ }^{4}$ Lahore School of Nursing, The University of Lahore, Pakistan
}

\author{
DOI: $10.36348 /$ sjnhc.2021.v04i04.003 \\ | Received: 23.02.2021 | Accepted: 04.03.2021 | Published: 21.04.2021
}

*Corresponding author: Yasmeen Ghafoor

\section{Abstract}

Nurses are the vital part of the health care departments and there is no doubt that nurses are the prime unit of the health care profession. According the world health statistics analysis there are approximately 29 million nurses worldwide and there is an estimation that one million nurses are further needed by the year of (2020) Shortage of nurses affect the country health care setting and significantly, it also affect the patient care which results in overall health decline in the whole country. Pakistan is also facing great challenges regarding the nursing profession and shortage of nurses is at the top of these challenges and nursing profession is female dominated profession which also increases the social cultural boundaries. As per results of a research conducting regarding Pakistan nursing work in overcoming the shortage of the nurses in the Pakistan as it is a big challenge faced by the Pakistan in the last decay. I feel very disappointment that in Pakistan this profession faces more problems/ shortage of nurses as compare to other countries. The facts and figures related to the health care in Pakistan are alarming and to handle these the health care provider and the government of Pakistan should take the strong steps. Due to this shortage patient care effects. The nursing workforce in Pakistan is 4.9: 10,000 (WHO, 2016) which indicates a shortage for a country with population of about 193 million (WHO, 2019). Unluckily, the education role of the nurses in Pakistan is not improper shape as it should be only good nurses can be produce by the good educator nurses. In the past nursing care was limited to the bedside patient care but now a days nursing research and advance studies have opened new horizons for the nurses in the country .

Keywords: Nurses, health care profession, Patient Care, WHO.

Copyright (C) 2021 The Author(s): This is an open-access article distributed under the terms of the Creative Commons Attribution 4.0 International License (CC BY-NC 4.0) which permits unrestricted use, distribution, and reproduction in any medium for non-commercial use provided the original author and source are credited.

\section{INTRODUCTION}

Nurses are the vital part of the health care departments and there is no doubt that nurses are the prime unit of the health care profession. According the world health statistics analysis there are approximately 29 million nurses worldwide and there is an estimation that one million nurses are further needed by the year of $2020[1]$.

Furthermore, world health organization has announced that due current crisis of pandemic six million more nurses will be required to full fill the health care standards in the health care setting and every country has to work domestically to increase their strength of numbers nurses and this will possible by investing more finance and attention to the profession of nurses [2].

Shortage of nurses highly affect the treatment of patient in care of patient involve the all care head to toe care when we discussed the care many factor involve time required to full fill all need time management is very significant. In nursing, nurse's works not only have lots of things to get done, but also enforced to make some decisions [3].

Nurse's shortage not only affect the patient care it affect the overall health care of any country there are many reason behind this critical shortage of nurse like low funding by the government, shortage of nursing school, low socio economic status and less scholarships for nursing students [4].

Shortage of nurses affect the country health care setting and significantly, it also affect the patient care which results in overall health decline in the whole country. Nurses shortage in the health care settings affect the health of nurses itself as it increases the work load which may result in the job stress, anxiety, over burden and physical issues as well mental health on the other those countries who have less shortage of nurses their nursing care is quite better because their nurs $3 \mathrm{~s}$ have less job stress and dissatisfaction [5]. 
Yasmeen Ghafoor et al., Saudi J Nurs Health Care, Apr, 2021; 4(4): 114-119

It has recognized that the shortage of nurses is affecting the quality care and even safety of patients life and those countries who are not putting enough stress to overcome the shortage of nurses they are giving their whole nation risk of death because if one staff nurse will monitor 70 to 80 patients in her duty she will not be able to provide even basic care and medications to whole patients [6].

Multiple factors causes the shortage of nurses which may be job dissatisfaction, less finical add, late promotion, less motivation, number of retirements increases the shortage because when country does not focus on new recruitments its increases the burden on the profession which also leads to the shortage of young employ [7].

Current shortage of nurses is also increasing the burden on patient care globally, because nurses are responsible to provide all type of care in health care settings and even in the home setting as public health nurses [8].

Pakistan is also facing great challenges regarding the nursing profession and shortage of nurses is at the top of these challenges and nursing profession is female dominated profession which also increases the social cultural boundaries. Gender biasness can also impact positively on the shortage of nurses. Negative image of the nursing profession also restrict the people thinking to be the part of the profession as nursing profession also bad image in the Pakistani culture and to some extant the media is responsible for this to communicate bad image in Pakistan in the long its creates the shortage of nurses [9].

In Pakistan nurses are not satisfied with their jobs this increases the frustration in the nurses which may lead to leave the nursing profession and it ultimately give raise to the shortage of nurses [9].

Moreover, shortage of nurses also increases the work load on the remaining nurses and its result in the poor patient care and when a country or health care setting fails to treat the sick patients due in insufficient health care professional there will be significant change in the mortality rates and higher death ratio means higher burden on the country [10].

Government sector and private sector also facing the shortage of nurses which ultimately results in poor patient care and over burden the nurses and it also increases the chance of medical errors [11].

According to WHO a wide system model to increase the health professionals, every country should focus on this model as this model focuses on the inflow and outflow of the nurses to supply better nurses in the whole country, every country should work to produce highly qualified nurses effort must make in the urban and rural areas. As every country faces the same problem in context of the shortage of qualified nurses [12].

A study was conducted which revealed in results that our social negative attitude is also responsible for the shortage of nurses in the Asian countries, because it is female dominant profession special in developing country and only one female staff have to attend 30 to 40 patients in her duty and nurses are responsible for their every action related to their patients, duties of nurses includes head to toe care, medication, surgical procedures and vital signs etc. And overburdened health care professional can make the medical errors very easily ultimately it increases the mortality rate [13].

Shortages of nurses puts negative affect on the patients care because exhausted nurses will not be able to provide best patients care and burden of nurses can only be decrease by producing the more nurses and improving the technology to help out nurses as it has been revealed in the research studies that satisfied health care professionals can give best services in the patients care and it is same scenario is with nurses. Furthermore, it is revealed in the research study that only satisfied nurses can provide best nursing care to the patients [14].

Satisfied workers can be produce by making the workers most satisfied by their jobs and job satisfaction can be achieved by giving the nurses reward, timely promotion and job security and satisfied nurses can provide best nursing care to the patients [15].

Shortage of nurses can be overcome by providing the empowerment to the nurses and healthy environment to the nurses which ultimately nurses satisfied with job and nursing care can be improved and patient safety can be provided [16].

Motivated nurses can work with highly efficient force and on the other hand demotivated nurses can cause unbearable mistakes that can take life of any person.

Now a days number of disease is increasing day by day and most populated countries need most efficient and well educated nurses to overcome the disease burden but when there is no choice only best educated work force of nurses can give strength to the patient centered care, patients centered care can be only possible if there is enough number of the nurses in both rural and cities [14].

Shortage of nurses can also raise many for the patients and for health care setting like medical error, negligence and malpractice which puts many lives in to the danger and nursing shortage and nursing school shortage and nurses educator shortage, Team work and 
Yasmeen Ghafoor et al., Saudi J Nurs Health Care, Apr, 2021; 4(4): 114-119

proper leadership of nurses can be helpful in improving care even with less man power because unity always in strength [17].

Nursing shortage is challenge which may affect the country health in different ways like by creating the more opportunities for nurses and nursing colleges for higher education, healthy and friendly work environment job security, better future opportunities and attractive salaries. Furthermore, motivation can play an important role in the all issues of shortage of nurses and many issues can be solve by health work environment and it will be helpful in the providing bets nursing care to all patients [15].

WHO wide health model for nurses can be really helpful in overcoming the shortage of nurses if higher authorities of nurses make this model into practice which is consist of three steps like pipeline nurses which are going through the basic nursing graduation, producing the higher educated nurse in the same time and replacing the retired work force by the new but well educated nurses through well-equipped and furnished nursing colleges [12].

Reducing the shifting of nurse to abroad can be really helpful for developing countries to overcome the all staff nurses shortage related issues but it can only possible by creating more opportunities for nurses in all regards of finance and healthy working environment and avoiding the stressful environment developing countries should pay special attention to stop high turnover of nurses [18].

Exhausted busy schedule must be divided in all health care workers equally so everyone must pay proper attention to the care of the patients it will also improve the care quality provided to the nurses [19].

Nurse's mangers and leaders can also play a vital role in the better patient care with less resources of equipment even with less human resources mangers should divide the all work in to team so everyone can provide best care to the patients [20].

Because when nurses are satisfied with their mangers they feel free to give their best on job but when nurses are tense this might affect the overall prestige of the health care setting.

laissez-faire style most of the time create friendly environment and it makes the people free to choose their own decision and make their own work environment according to their style but it create problem for the nurses but every nurse cannot be able to overcome every stressful situation (indeed.com, 2020).

Transformational leader ship style help the nurse manger to create the best working environment for the nurses. Which make the nurses motivate to work and to create opportunities for the nurses if nurse mangers give the flexibility to their nurses who working under their supervision because nurses better supervision can be helpful in providing best nursing care to the patients in hospitals and communities [21].

Nurse's leaders who prove their self like the motivation and simulation can be the best leader in the health profession because when exhausted work and duties make the nurses uncomfortable and dissatisfied with their jobs [22].

\section{Challenges in the Nursing profession}

According to the American Association of Colleges of Nursing the count of nurses who are leaving their profession is increasing day by day approximately, 40,000 in 2010 to nearly 80,000 by 2020 . and situation is becoming worse day by day and in fact in the time of the pandemic nurses are at risk so, every country put special attention to their nursing profession.

Shortage of any professionals put the whole profession at risk because less work force might affect the whole image of the profession likewise nurses can't give best quality care to their patients.

As per results of a research conducting regarding Pakistan nursing work in overcoming the shortage of the nurses in the Pakistan as it is a big challenge faced by the Pakistan in the last decay, But the situation is improving day by day with the commute effort of the nursing higher authorities with the collaboration of the government.

Major challenges face by the Pakistani nurses are job dissatisfaction, harassment and shortage problem may be improve by providing best and attractive jobs opportunities and rewards will improve the overall problems of the nursing profession [23].

Clinical nurses are considered as most sensitive nursing section because they are directly attach to patient care but unfortunately clinical nurses are dissatisfied due to over burden. They are also at great risk of infection because directly attach to the patients .government should give the best attention to the clinical nurses.

Nurses' care is essential at bedside to their skills to certify patient safety. It is rational therefore that transfer grown no of patients finally negotiation nurse ability to deliver safe care. Have proved the connection between

Nurses' ratio and patient care. Recording a bigger treat of patient safety action. Illness and death as the figure of patient per nurses rise.

The have patient relation is first one feature of the association among nursing workload and patient 
Yasmeen Ghafoor et al., Saudi J Nurs Health Care, Apr, 2021; 4(4): 114-119

care.nusring workload is probable related to patient effect as fine. Bigger patient turnover was also linked with increase mortality risk. Nursing expertise combination and training connected to patient effects. The value of nurses on job teaching also show a part in patient care.

The contributing connection among nurse to patient ratio and patient sound effects probable is accounted for by both increased pressure and risk of stress for nurses' .lost nursing care a type of blunder of lapse in which required care basics are not ended is common inpatient wards

The nature of nurse work resources that nurses themselves are at risk of mistakes though providing routine care. Mostly medication directing errors. Some interval are likely important for patient care .nurses is directly linked to patient safety. All factor the high risk nature of the work stress caused by work load and interludes and also risk of fatigue due to involvement in mistakes .low nurse to patient ratio to increase the risk of adverse events.

The national wide quality recommended in tented consensus value for having sensitive care. These involved patient involved outcomes measured to be signs of nursing care quality such as history of fall and bed sores method linked measures includes having skill mixture nursing care processes of the excellence of nursing practice and nursing shortage.

The magnet hospital recognition program provide greater patient care on this base attract and maintain high quality nurses. Proper nursing staff is necessary to improve patient care. Most essential for high quality care has been set. Nursing staff is complex and use of ratio generalize the solation in organization where the nurses numbers are supplied a greater part of nurses with work experience may help reduce the fall rate in hospital ward.

Excellence of care is worldwide health urgency for health organization certify the patient safty.

Quality is centered on an active contact between organization and care practice.in all hospital must have sufficient multi professional team administrative structure and care delivery practice to meet the growing health care needs maintain sufficient level of quality and safety. Nurses are largest group of health specialists playing a vital role in the upgrade of high quality care and patient safety. Nurses' level are essential to encounter the patient requirement and

Supply safe and quality care most important the idea of safe staff in nursing. Nurse leader had a high level of arrangement regarding the deal in continuing professional training as the nurses have the necessary skills for nurse's practice are able to provide needs patient observation and use available tools in the decision making procedure and in the provision of care.

The shortage of nurse's current background there is an urgent need to consideration human resources management strategies. Given the difficulty health system it was important to best understand potential weaknesses and strength with drive of decreasing the risk associated care.

Distribution and improving its quality. The mangers and policymaker mainly because it provide information about the aspect that guidance the quality of nursing care .establish on facts it will be possible to improvement.

Struggle to incessantly improve the quality of health care .nurse manager play very important role in encourage the team engagement to improve the care process. Doctors and nurses are frontline health care experts that deliver the common of care they receive patient in hospitalization. Communication and teamwork between them in critical it can affect the quality of care patient safety and satisfaction of nursing staff and their wish to leave the work [24].

About the patient safety indicators folly's catheter associated infection was most repeatedly reported indicator by nurses $52.8 \%$ reported it as very frequent and other indicator was bed sore as about $43.4 \%$ of participants reported it as very frequent. Patient safety indicators frequently.

The nurse supervisor's skills and leadership and strong bedside nurse relation are two of the most significant variable in the struggle of healthworker to deliver quality care [25].

\section{Sharing the Vision}

When I relate the shortage of nurses with other countries I feel very disappointment that in Pakistan this profession faces more problems/ shortage of nurses as compare to other countries. The facts and figures related to the health care in Pakistan are alarming and to handle these the health care provider and the government of Pakistan should take the strong steps.

Due to this shortage patient care effects. The nursing workforce in Pakistan is 4.9: 10,000 [26] which indicates a shortage for a country with population of about 193 million [26].

Unluckily, the education role of the nurses in Pakistan is not improper shape as it should be only good nurses can be produce by the good educator nurses. In the past nursing care was limited to the bedside patient care but now a days nursing research and advance studies have opened new horizons for the nurses in the country. 
Yasmeen Ghafoor et al., Saudi J Nurs Health Care, Apr, 2021; 4(4): 114-119

Stakeholder: who and why?

In my vision the stakeholder in the health care system would include the all health professional such as doctors, controlling, and financial authorities. Sharing of vision with health care provider and stakeholders encouraging them to change the healthcare system in the Pakistan. Regulatory bodies should encourage the nurses by providing them the best platform to perform their duties which also very helpful the control the shortage of nurses.

The teaching institutes and hospital administrator should also include in sharing of the vision so that the nurses' career should be planned out for placing the experienced nurses on senior positions in hospital administration and teaching institutions. Electronic and print media should also involve to share the vision to spread it and national as well as international level.

\section{REFERENCE}

1. Haddad, L. M., Annamaraju, P., \& Toney-Butler, T. J. (2020). Nursing shortage. In StatPearls [Internet]. StatPearls Publishing.

2. World Health Organization. (2019). Global status report on alcohol and health 2018. World Health Organization.

3. World Health Organization. (2020). Coronavirus disease 2019 (COVID-19): situation report, 82.

4. McKechnie, T. (2016). Call for nurses: The multidimensional manifestation of nursing shortage on patient care. QIHI Journal of Healthcare Improvement and Patient Safety, (2).

5. Mark, D. B., Anstrom, K. J., Sheng, S., Piccini, J. P., Baloch, K. N., Monahan, K. H., ... \& Packer, D. L. (2019). Effect of catheter ablation vs medical therapy on quality of life among patients with atrial fibrillation: the CABANA randomized clinical trial. Jama, 321(13), 1275-1285.

6. Goodare, P. (2017). Literature review: Why do we continue to lose our nurses? Australian Journal of Advanced Nursing, 34(4), 50.

7. Jarrar, M. T., Rahman, H. A., Minai, M. S., AbuMadini, M. S., \& Larbi, M. (2018). The function of patient- centered care in mitigating the effect of nursing shortage on the outcomes of care. The International journal of health planning and management, 33(2), e464-e473

8. Weaver, M. S., Wichman, B., Bace, S., Schroeder, D., Vail, C., Wichman, C., \& Macfadyen, A. (2018). Measuring the impact of the home health nursing shortage on family caregivers of children receiving palliative care. Journal of Hospice and Palliative Nursing, 20(3), 260.

9. Abbas, S., Zakar, R., \& Fischer, F. (2020). Qualitative study of socio-cultural challenges in the nursing profession in Pakistan. BMC nursing, 19, 1-7.

10. Duffin, J. (2014). To see with a better eye: A life of RTH Laennec. Princeton University Press.
11. Cox, E., Bachkirova, T., \& Clutterbuck, D. A. (Eds.). (2014). The complete handbook of coaching. Sage.

12. Drennan, V. M., \& Ross, F. (2019). Global nurse shortages - the facts, the impact and action for change. British medical bulletin, 130(1), 25-37

13. Nasurdin, A. M., Tan, C. L., \& Khan, S. N. (2020). The Impact of Social Support on Nurses' Motivation: A Cross-Sectional Study in Malaysia. Asia Pacific Journal of Public Health, 1010539520965026.

14. Maurits, E. E., de Veer, A. J., van der Hoek, L. S., \& Francke, A. L. (2015). Factors associated with the self-perceived ability of nursing staff to remain working until retirement: a questionnaire survey. BMC Health Services Research, 15(1), 111.

15. Ghafoor, S., Ghafoor, Y., Bhatti, N. M., Hussain, M., Arshad, T., \& Bilal, A. (2017). Impact of Motivation on Job Satisfaction among Nurses of Services Hospital Lahore. Pakistan Journal of Medical \& Health Sciences, 11(2), 532-536.

16. Melanson, D. L. (2012). Using empowerment to build trust and respect in the workplace: a strategy for addressing the nursing shortage.

17. Fainguersch, B. A. (2020). The Impact of the Nursing Shortage on the Quality of Care of Veterans.

18. Chan, C. C., McBey, K., Basset, M., O’Donnell, M., \& winter, R. (2004). Nursing crisis: retention strategies for hospital administrators. Research and Practice in Human Resource Management, 12(2), 31-56.

19. Wells-English, D., Giese, J., \& Price, J. (2019). Compassion fatigue and satisfaction: Influence on turnover among oncology nurses at an urban cancer center. Clinical journal of oncology nursing, 23(5), 487-493.

20. Kramer, L. D. (2004). The people themselves: popular constitutionalism and judicial review. Oxford University Press.

21. Shelly, S., \& Babu, A. V. (2017). Link residual lifetime-based next hop selection scheme for vehicular ad hoc networks. EURASIP Journal on Wireless Communications and Networking, 2017(1), 1-13.

22. Jafree, S. R. (2017). Workplace violence against women nurses working in two public sector hospitals of Lahore, Pakistan. Nursing outlook, 65(4), 420-427

23. Khowaja, A. A., Rafiq, N., Rabi, F., Merchant, N., Rafiq, N., \& Zulfiqar, S. (2019). Turnover propensity among nurses in Pakistan: Overview and management. Iris Journal of Nursing \& Care, 1(2), 1.

24. Alhamdan, A., Hassan, B., Alkahtani, H., Abdelkarim, D., \& Younis, M. (2018). Freezing of fresh Barhi dates for quality preservation during frozen storage. Saudi Journal of Biological Sciences, 25(8), 1552-1561. 
Yasmeen Ghafoor et al., Saudi J Nurs Health Care, Apr, 2021; 4(4): 114-119

25. Flynn, L., Liang, Y., Dickson, G. L., Xie, M., \& Suh, D. C. (2012). Nurses' practice environments, error interception practices, and inpatient medication errors. Journal of Nursing Scholarship, 44(2), 180-186.
26. World Health Organization. (2016). Global health sector strategy on viral hepatitis 2016-2021. Towards ending viral hepatitis (No. WHO/HIV/2016.06). World Health Organization. 